\title{
DAS FANTASIAS VAZIAS AO REFERENCIAL DISCURSIVO
}

Ricardo Salztrager

Psicanalista; mestre

e doutor pelo

Programa de Pós-

graduação em Teoria

Psicanalítica da

Universidade Federal

do Rio de Janeiro.
RESUMO: Pretende-se analisar o estatuto de uma modalidade peculiar de fantasmatização para a qual propomos o nome de 'fantasias vazias'. No campo das fantasias vazias, a ambigüidade e a polissemia das palavras são postas de lado e seus enunciados se tornam absolutos e unívocos, de modo a anularem quaisquer possibilidades metafóricas ou simbólicas. Investigamos os limites que as fantasias em questão impõem à teoria do significante, propondo, em seguida, concebêlas como uma escritura balizada por uma série de elementos que denominamos 'referenciais discursivos'.

Palavras-chave: Fantasia, significante, metáfora, metonímia, psicanálise.

ABSTRACT: From empty fantasies to dissertational reference. The purpose of the article is to analyze the state of a peculiar modality of fantasizing which we have named empty fantasies. Thus, in the field of empty fantasies, the ambiguity and the multiple meaning of the words are put aside and, for that reason, their statement becomes obsolete and univocal, in a way that they eliminate any metaphoric or symbolic possibilities. We investigate the limits that those fantasies impose to the theory of the signifier, proposing, then, to conceive them as a writing delimitated by a series of elements that we have called discourse references.

Keywords: Fantasy, signifier, metaphor, metonymy, psychoanalysis. 
Om freqüência, nos deparamos na clínica com determinadas produções fantasísticas frente às quais o dispositivo analítico, de certo modo, vacila. Trata-se de fantasias conscientes, expressas pelo sujeito com certa naturalidade e que surgem sempre apartadas do restante de suas produções discursivas: "fantasiei que estava num vazio" ou "fantasiei que estava num buraco negro". O fator marcante em construções fantasísticas deste tipo remete à escassez de associações produzidas a partir de seus relatos, parecendo impossível ao paciente remeter, por exemplo, o "vazio” ou o “buraco negro” a quaisquer outros significantes. Isto dificulta o trabalho de interpretação e impõe um sério obstáculo aos progressos analíticos. Às formações fantasísticas desta espécie proponho o nome de "fantasias vazias".

O termo 'vazio'1 está sendo empregado para qualificar essas fantasias devido à observação clínica de que elas se mostram, antes de tudo, como organizações psíquicas esvaziadas de uma narrativa. Ou seja, não se trataria, neste domínio fantasístico, da constituição de uma história, romance ou teorização. Pelo contrário, as fantasias vazias remetem à simples produção de cenas nas quais se manifestam algumas imagens fixas e dissociadas umas das outras. Conforme assinala Pinheiro (2002), elas também possuem uma relação bastante peculiar com a temporalidade pois, por não se configurarem enquanto história, não se reportam à idéia de uma continuidade temporal, na qual uma cena iria se sucedendo à outra, de modo a estabelecer um vínculo de causa e efeito entre seus elementos.

O atributo de vazio também se remete a essas fantasias na medida que, a partir de seus relatos, as associações livres são quase nulas, ou mesmo inexistentes. Em decorrência disto, a cena anestesiada não conduz a lugar algum, a nenhuma outra fantasia ou formação psíquica. Durante a descrição da cena, o discurso torna-se congelado e imobilizado em torno de uma mesma frase. É igualmente importante delimitar a freqüência com que elas se repetem no discurso, mas, ainda assim, nenhum outro componente lhes é associado. São sempre as mesmas cenas paradas e apáticas que, embora recorrentes, se perpetuam na fala tal como relatadas pela primeira vez. Estas fantasias são também esvaziadas de predicados, coloridos ou detalhes; enfim, de tudo o que poderia funcionar como brecha para a interpretação. Da mesma forma, símbolos e metáforas são elementos ausentes em seus conteúdos.

Com base nestas considerações, verificamos que se, por um lado, estas fantasias são esvaziadas de narrativas, de símbolos e de associações, por outro, elas consistem em formações psíquicas já plenas de significação. Ou seja, elas se apresentam ao analista como estruturas cujas significações são dadas de antemão,

\footnotetext{
${ }^{1}$ Para uma abordagem mais ampla acerca da temática do vazio no pensamento psicanalítico, ver Herzog (1999).
} 
no próprio instante da enunciação. Com efeito, esta é a característica que mais nos intriga, pois o fato de a descrição da fantasia vazia soar como algo extremamente claro e não enigmático implica sua distinção das demais modalidades fantasísticas abordadas pelo pensamento freudiano, sejam estas referentes às lembranças encobridoras (FREUD, 1899/1995), aos devaneios (FREUD, 1908a/1995), às fantasias inconscientes subjacentes aos sintomas (FREUD, 1908b/1995) e às criações artísticas (FREUD, 1910b/1995) e mesmo aos fantasmas originários (FREUD, 1918/1995).

De fato, ao contrário do que ocorre nestas outras produções fantasísticas, no campo das fantasias vazias, a ambigüidade e a polissemia das palavras são postas de lado e, assim, seus elementos se tornam absolutos e unívocos, de modo a anularem quaisquer possibilidades metafóricas ou simbólicas. Em outros termos, estas fantasias não abrem espaço para a dúvida, o vacilo ou o tropeço, como se seus componentes estivessem atados a uma significação rígida e fixa. Com efeito, esta delimitação que estamos traçando no domínio fantasístico do sujeito é um corolário de experiências clínicas com pacientes que possuem um discurso pouco metaforizante. Mesmo em sujeitos que apresentam um discurso bastante rico do ponto de vista devaneativo, o analista atento perceberá determinados núcleos, em seus enunciados, nos quais uma fala até então bastante fértil se converte num emaranhado de ditos anestesiados e neutralizantes. As fantasias vazias não se vinculam, portanto, a nenhuma estrutura clínica em particular, estando presentes nos mais variados sujeitos que procuram tratamento analítico. ${ }^{2}$

Para ilustrar esta formação psíquica que designamos de fantasias vazias, remetemos à obra freudiana, mais especificamente à "Análise de uma fobia em um menino de 5 anos” (FREUD, 1910a/1995). Trata-se de uma cena relatada por Hans a respeito do cavalo que possuía um estranho objeto preto na boca, objeto que o menino não conseguia associar a nenhuma outra representação. Apesar das múltiplas tentativas de Freud e de seu pai, a criança dizia que o referido objeto não simbolizava, de modo algum, um arreio, um bigode ou qualquer outro elemento. Sempre que o trabalho associativo esbarrava neste estranho objeto preto, o discurso de Hans, até então bastante fértil, tornava-se congelado. Da mesma maneira, sempre que a cena retornava no discurso, as mesmas reticências se manifestavam. A cena, em si, já era clara, não fazia enigma e se mostrava irredutível aos esforços interpretativos e da livre associação. ${ }^{3}$

Assim, tendo em vista a inespecificidade conceitual desta modalidade fantasística, nossa proposta aqui é oferecer uma circunscrição metapsicológica para as fantasias vazias. Mais especificamente, pressupondo que, em seus domínios,

\footnotetext{
${ }^{2}$ Para maiores detalhes acerca da função das fantasias vazias na dinâmica de funcionamento do aparelho psíquico, remeto a Salztrager (2006).

${ }^{3}$ Retomaremos adiante este fantasma de Hans, a fim de melhor analisá-lo.
} 
os enunciados se manifestam de forma unívoca e já plena de sentido, investigaremos os limites que elas impõem à teoria do significante, tal como concebida por Lacan. Isto porque o pensamento lacaniano preconiza que o significante não remete a um significado a priori, mas se articula com outros componentes da cadeia para produzir a significação. Com efeito, conforme o exposto antes, as fantasias vazias não entram em associação com o restante da cadeia fantasística do sujeito, e isto implicaria na sua irredutibilidade ao domínio significante. Ademais, o fato de seus elementos já se encontrarem atados a uma significação rígida e fixa também parece apontar para uma outra modalidade de estruturação discursiva que não a significante.

Desta forma, ao pressupor que as fantasias vazias escapam à lógica do significante, iremos concebê-las, no decorrer do artigo, enquanto uma escritura psíquica peculiar balizada por uma série de elementos a serem denominados de referenciais discursivos. Com isto, nos reportamos a alguns componentes da fala que se comportam à maneira de referenciais, que não cessam de reenviar a si próprios, não circulando na cadeira discursiva e nem remetendo aos demais enunciados do sujeito. Assim, ao trazer para o primeiro plano da discussão a noção de referencial discursivo, estaremos mostrando que nem tudo no campo enunciativo deve ser necessariamente reduzido ao domínio significante. Trata-se, em outros termos, de repensar uma tendência bastante operante no pensamento psicanalítico na medida que, pelas fantasias vazias reenviarem a uma significação já dada, elas passariam à margem dos trabalhos da metáfora e da metonímia próprias ao plano significante.

\section{SOBRE A LÓGICA SIGNIFICANTE}

Visando analisar os limites que as fantasias vazias impõem ao campo significante, devemos, num primeiro momento, nos debruçar sobre os principais pressupostos teóricos próprios a este domínio. Para tal, nos serviremos do ensaio "A instância da letra no inconsciente ou a razão desde Freud” (LACAN, 1957/1998), no qual é preconizado, a partir de uma proposta de subversão do pensamento saussuriano, que o significante se encontra dissociado do significado, possuindo, sobre este, uma primazia. Trata-se, em outros termos, de destacar que o significante não remete diretamente a nenhum significado; mas, se articula com outros significantes na forma de uma cadeia para produzir o fenômeno da significação. Conforme a passagem a seguir:

“se pode dizer que é na cadeia do significante que o sentido insiste, mas que nenhum dos elementos da cadeia consiste na significação de que ele é capaz nesse mesmo momento. Impõe-se, portanto, a noção de um deslizamento incessante do significado sob o significante." (LACAN, 1957/1998, p.506, grifo do autor) 
A partir desta formulação, Lacan (1957/1998) estabelece que o significante não é o signo e nem sinal da coisa, retirando deste registro qualquer pretensão de fornecer uma significação absoluta a determinado fenômeno. Ou seja, o significado - tido como o sentido por todos compartilhado de dada experiência — é posto de lado e, conseqüentemente, o significante passa a resistir ao processo de significação. Assim, concebe-se que o significante não possui, de forma alguma, uma significação intrínseca, perdendo a sua função de representar o significado. Nesta perspectiva, ele apenas ocuparia uma posição ou um lugar numa cadeia discursiva; e o sentido seria criado a partir da combinação entre os elementos da rede de linguagem.

Deste raciocínio resulta a lei da primazia do significante frente ao significado. Conforme assinala Lacan (1957/1998), nunca devemos imaginar um significante sozinho na medida que ele somente o é, e assume sua função, na relação com alguns outros significantes a ele encadeados. Conseqüentemente, seriam as redes de permutas próprias a este domínio o que produziria a significação, como se o significante preexistisse ao significado. Assim, pressupondo ser a ausência de significação aquilo que fundamenta o advento da cadeia significante, motivando-a e impondo suas permutas, conclui-se, de acordo com o pensamento lacaniano, que o sentido é sempre um resultado, um efeito ou, mais especificamente, uma criação. Em outros termos, pensar a dinâmica discursiva enquanto um conjunto de tramas e redes significantes entrelaçadas conduz à proposta de encarar o sentido como algo construído pelo sujeito, e não como uma formação já dada, perdida e à espera de ser revelada.

Deste modo, sendo as permutas manifestas no campo significante o que torna possível o efeito de significação, Lacan (1957/1998) recorre a algumas diretrizes presentes nos trabalhos de Jakobson (1963), a fim de explicitar os processos lingüísticos subjacentes a estas operações de permuta. A conclusão obtida remete à descrição dos mecanismos da metáfora e da metonímia como os responsáveis, respectivamente, pelos trabalhos de substituição e de combinação significante. Ou seja, segundo o lingüista, o discurso seria orientado por dois eixos: o eixo paradigmático que abrange o tesouro da linguagem e do qual selecionamos um termo entre outros para construir nossa fala; e o eixo sintagmático, referido ao arranjo das unidades lingüísticas escolhidas umas com as outras. O eixo paradigmático, associado à sincronia, viabiliza a substituição dos termos entre si, de modo que um termo leve ao outro pela similaridade existente entre eles. Já o eixo sintagmático está ligado às articulações dos elementos escolhidos, estabelecendo entre eles uma relação de contigüidade. Com base nestes pressupostos, conclui-se que os processos metafóricos se associam ao eixo paradigmático e as operações metonímicas se vinculam ao eixo sintagmático. 
Assim, apoiado nestes estudos, Lacan (1957/1998) define o processo metafórico como o trabalho de substituição de um significante por outro que tenha com o primeiro uma relação de similaridade; a operação metonímica, por sua vez, seria a responsável pela própria conexão entre os significantes na cadeia. Deste modo, a metáfora é o mecanismo que implanta um significante na rede discursiva, significante este que assume o lugar de um outro, fazendo-o passar para um estado latente. Já a metonímia viabiliza o encadeamento de um significante a outro, combinando termos provenientes de diferentes registros. Em si, o processo metonímico é aquele que se define por levar de um significante a outro mas, diferentemente do que ocorre na metáfora, a substituição significante não faz com que o primeiro fique em estado latente; pelo contrário, eles permanecem em contigüidade um com o outro. Nesta medida, o procedimento metonímico torna viável ao discurso desdobrar-se no tempo, pois assim, determinado enunciado vai estar sempre ligado a outro por contigüidade, numa seqüência infinita de rearranjos narrativos.

Como no procedimento metonímico o significante substituído permanece em associação de contigüidade com aquele que o substitui, conclui-se que, mediante o artifício da associação livre, é permitido ao sujeito passar de um a outro, evocando-o durante o tratamento analítico. Assim, devemos ressaltar que o discurso se apresenta como uma estrutura passível de interpretação, justamente, por estar articulado pelas leis da metonímia. Nesta medida, caberia à interpretação psicanalítica avançar por entre os meandros do encadeamento metonímico, desmontando estes circuitos e, conseqüentemente, promovendo o advento de um novo rearranjo do material discursivo.

Desta maneira, o discurso do sujeito, como um todo, repousaria sobre o fenômeno da sobredeterminação, tal como Freud (1900/1995) postulou em relação aos sonhos. Ou seja, pelo fato de os enunciados subjetivos estarem entrelaçados por uma infinidade de deslocamentos metonímicos, seria impossível ao procedimento analítico substituir um significante por um único significado. Pelo contrário, a interpretação psicanalítica tem por função a desconstrução de um cenário discursivo para que ele se abra em direção a uma pluralidade de outros significantes que, por sua vez, remeterão a outros significantes, e assim por diante. ${ }^{4}$

\section{A QUESTÃO DO REFERENCIAL DISCURSIVO}

A partir destas considerações, se retomarmos o caso do pequeno Hans, podemos vislumbrar o embasamento significante em grande parte das produções fantasísti-

\footnotetext{
${ }^{4}$ Para maiores detalhes acerca de como a interpretação psicanalítica merece ser encarada como um processo de desconstrução discursiva, remeto o leitor a Foucault (1987).
} 
cas do menino. Segundo Freud (1910a/1995), uma série de fantasias justificava o quadro clínico de fobia a cavalos, sendo o objeto fóbico um substituto metafórico da figura paterna. Nesta perspectiva, a visão de um cavalo morrendo faz surgir um desejo de morte do pai e o processo metafórico é motivado por algumas semelhanças entre o cavalo e a figura paterna: o pai, por exemplo, quando bravo, batia as pernas severamente tal qual um cavalo.

Ao longo da história clínica, verificamos também que o pai não era simbolizado nas fantasias de Hans apenas pelo cavalo, pois, numa outra fantasia, é a girafa o animal que aparece simbolizando a figura paterna. Nesta, havia duas girafas no quarto da criança - uma grande e outra amarrotada - e quando Hans senta em cima da girafa amarrotada, a outra se põe a gritar, pois havia sido levada para longe da companheira. De acordo com Freud (1910a/1995), o conteúdo fantasístico que assoma à consciência consistiria num substituto disfarçado de outra fantasia inconsciente composta pelo desejo de tomar posse (sentar em cima) da mãe (girafa amarrotada) para desespero do pai (girafa grande). Também, em suas fantasias, a irmã Hanna era constantemente associada a um lumf (fezes).

Deste modo, vemos que, nas fantasias de Hans, o significante 'pai' serve de suporte para uma série de operações metafóricas, fazendo erigir, a cada substituição significante, uma nova retranscrição do material psíquico e, conseqüentemente, um novo remanejamento fantasístico. A primeira substituição ocorre entre os significantes 'pai' e 'cavalo', e quando o segundo entra na cadeia no lugar do primeiro, este é jogado para o inconsciente; o mesmo processo pode ser vislumbrado na fantasia das girafas, quando os significantes 'girafa grande' e 'girafa amarrotada' assumem, respectivamente, o lugar dos significantes 'pai' e 'mãe'; o significante 'Hanna' também é substituído por 'lumf' por intermédio de uma operação metafórica, na medida que entre eles existe uma relação de semelhança: os dois sairiam do corpo da mãe da mesma maneira.

Os processos metonímicos também se fazem sentir na cadeia fantasística de Hans, justificando, mais uma vez, seu embasamento significante. Assim, nas fantasias da criança, as operações metonímicas ligam um significante a outro promovendo, no discurso do menino, o advento de uma trama fantasística temporalizada e historicizada. Ou seja, é pelos significantes estarem atados uns aos outros por intermédio de elos metonímicos que as fantasias do menino assumem o colorido de um romance: desta forma, uma cena da fantasia é causa de outra que, por sua vez, motivará a cena seguinte, e assim por diante. Neste contexto, o trabalho da metonímia faz erigir um remetimento mútuo entre todas das construções fantasísticas da criança, tornando possível tanto o trabalho de interpretação quanto a sua atividade correlata, a associação livre.

No entanto, devemos salientar que, ao lado destas produções fantasísticas bastante férteis, uma outra cena - aquela referente ao cavalo com o estranho 
objeto preto ao redor da boca — sempre aparecia no discurso de Hans, funcionando como um empecilho para a livre associação e também para a interpretação psicanalítica. Com efeito, a cena em questão contrastava com os demais romances fantasísticos inventados pela criança: enquanto estes últimos eram ricos e serviam de cenários para a realização de desejos e correções da realidade insatisfatória, a fantasia em questão se manifestava simplesmente enquanto uma cena neutra, fixa e sem coloridos ou predicados. Nem se conseguia, ao certo, dizer qual a sua função na dinâmica psíquica do menino, ou seja, se ela servia à realização de desejos ou à correção da realidade insatisfatória, pois o tratamento sempre vacilava nas tentativas de descobrir qual o seu papel na história do caso clínico.

Ademais, vislumbramos que o constante remetimento do cavalo à figura paterna vacilava sempre que o pequeno Hans falava sobre o objeto preto que o cavalo tinha na boca. De fato, os cavalos que o menino mais temia eram aqueles com o estranho objeto preto ao redor dos lábios; mas, no entanto, ele não sabia dizer que enigmático objeto era este e nem associá-lo a coisa alguma. Sempre que o discurso de Hans esbarrava neste ponto, as associações, até então abundantes, tornavam-se nulas. E por mais que seu pai ou o próprio Freud insistissem em relacionar o objeto preto na boca do cavalo com o bigode do pai, os esforços eram em vão. Hans respondia apenas com reticências. Assim, ao que tudo indica, a estranha coisa preta na boca do cavalo não consistia em nenhuma formação simbólica. Parecia impossível substituí-la por qualquer elemento inconsciente. Sempre que o menino falava sobre esta enigmática coisa preta, todo o discurso se congelava numa mesma cena anestesiada: a de um cavalo com um preto na boca, cena esta da qual nada mais conseguia dizer.

Nesta medida, percebemos o contraste desta cena anestesiada com as demais produções fantasísticas extremamente numerosas e férteis da criança. Enquanto os devaneios ou lembranças encobridoras de Hans remetiam a romances por ele inventados, visões sobre os mais variados fenômenos presentes em seu mundo e anseios sobre o futuro, nada disso pode ser observado na cena anestesiada do cavalo com o objeto preto na boca. Igualmente instigante é o fato de, frente aos devaneios ou lembranças encobridoras do menino, o tratamento analítico avançar com maior ou menor dificuldade, driblando as resistências e fazendo com que a criança se defronte com as tendências inconscientes que justificam a formação da fobia; de modo contrário, frente à cena anestesiada, as associações vacilam e, deste modo, a interpretação não podia avançar. A nada o menino conseguia remeter o preto na boca do cavalo; nenhum outro elemento lhe era relacionado.

Assim, por tais fatores, podemos traçar uma correlação entre esta cena fantasística de Hans e o que estamos denominamos de fantasias vazias: em ambos os casos temos a produção de cenas extremamente claras, nas quais salta aos 
olhos a ausência de símbolos ou formações metafóricas. Com efeito, conforme assinalamos aqui, no domínio das fantasias vazias também não há o remetimento metonímico de um elemento ao outro, o que anularia o fenômeno da sobredeterminação. Tampouco, observa-se a configuração de uma formação simbólica passível de ser instaurada por uma operação metafórica.

Com base nesta argumentação, podemos arriscar a hipótese de trabalho de que as fantasias vazias parecem encontrar seus alicerces numa outra forma de escritura que não a significante. ${ }^{5}$ No entanto, se estamos pressupondo que as fantasias vazias escapam à lógica significante e não se reduzem às leis próprias a este campo, devemos questionar a qual domínio discursivo elas se reportam. Ou seja, se, de acordo com nossa argumentação, a metáfora e a metonímia não são os processos lingüísticos que lhes fundamentam, cabe agora tentarmos delimitar alguns pontos de apoio que auxiliem no objetivo de circunscrever o regime lingüístico que serve de alicerce para a produção das fantasias vazias.

Nesta perspectiva, a proposta é caracterizar estas fantasias como uma escritura balizada por uma série de elementos que se comportam, na fala, à maneira de um referencial discursivo. Trata-se aqui de elementos que, no seio do discurso do sujeito, não cessam de reenviar a si próprios, possuindo uma significação clara e não ambígua. Os elementos destes enunciados não circulariam e nem remeteriam aos demais componentes do discurso - tal como ocorreria numa escritura significante - , sendo que a linguagem torna-se exata e sem equívocos em virtude de seu congelamento em torno destes referenciais. De acordo com esta concepção, os elementos discursivos em questão se reportariam sempre a eles próprios e não a um substituto metafórico, não se prestando, portanto, ao processo de formação simbólica.

Com efeito, a noção de referencial discursivo está sendo trazida para o primeiro plano da discussão, justamente, para tentarmos escapar de um ponto de vista que possa conduzir a encarar as fantasias vazias enquanto uma escritura de signos propriamente ditos. De fato, o registro do signo é caracterizado como contraposto ao campo significante; mas, nem por isso, devemos apressadamente correlacionar as fantasias vazias à economia do signo, posto que o regime em questão sempre aponta para um fragmento de realidade a ser representado pelo sujeito. Ou seja, de acordo com a semiótica de Peirce (1897/2003), o signo re-

\footnotetext{
${ }^{5}$ Neste aspecto, cabe assinalar, que nem por isso devemos classificá-las enquanto expressões fantasísticas mais rudimentares ou então residuais, tal como a leitura feita por Lacan (1956-1957/1995) acerca do fantasma neutralizante de Hans. Tratar-se-ia, apenas, de uma configuração fantasmática distinta daquelas com as quais nos deparamos a todo momento na clínica - sejam elas referentes, por exemplo, aos devaneios ou às lembranças encobridoras - justamente, porque apresentam um embasamento distinto daquele observado no domínio significante.
} 
envia ao objeto autêntico, havendo, portanto, um pressuposto realista subjacente a este domínio. Assim, se circunscrevêssemos uma analogia entre as fantasias vazias e o registro do signo, estaríamos indo justamente contra os propósitos de afirmar que estas cenas neutralizantes e anestesiadas fazem referência a um campo fantasmático.

Desta forma, a noção de referencial discursivo é mais condizente com nossa argumentação posto que, por este viés, passaríamos à margem deste fragmento de realidade que sempre acompanha uma teorização acerca de uma escritura de signos. Mas, neste sentido, cabe indagar: o que vem a ser um referencial discursivo? Por que este regime se diferencia do domínio significante? Será que conseguimos encontrar, na literatura psicanalítica, alguns alicerces que auxiliem na circunscrição metapsicológica desta noção?

Um retorno ao ensaio "Contribuição à concepção das afasias" (FREUD, 1891/1987) pode ajudar em nossos propósitos. No texto em questão, Freud analisa, pela primeira vez, a questão da representação em psicanálise, traçando uma série de críticas às concepções dominantes até então sobre o tema. Dentre todas as suas apreciações, duas são de fundamental importância: a primeira diz respeito à recusa em aceitar a representação como uma cópia ou mero simulacro da impressão; já a segunda remete ao fato de ele afirmar que a apreensão da realidade pelo sujeito nunca se dá de maneira uniforme e linear. Assim, de acordo com a visão freudiana, uma representação psíquica deixa de ser contemplada como o simples efeito mecânico do dado sensorial; pelo contrário, uma série de operações psíquicas interfere na condução de uma impressão, operações estas que correspondem aos processos de associação. Portanto, passa a ser impossível separar as funções psíquicas de representação e de associação, sendo a representação sempre pensada enquanto uma organização complexa na medida que se faz a partir da reunião e da combinação dos diversos elementos presentes em sua estrutura.

Tal como foi demonstrado no conhecido esquema psicológico do texto em questão, a palavra é definida como uma representação complexa e sua significação decorre de sua articulação com o que foi designado como representação-objeto (FREUD, 1891/1997). Neste contexto, também se assinala que a representaçãoobjeto não consiste num dado a priori; pelo contrário, ela só ganha existência efetiva a partir da ligação com a representação-palavra. Trata-se, em outros termos, de destacar que é somente a partir de suas relações com a representação-palavra que o objeto ganha uma unidade e uma identidade.

Segundo a leitura de Garcia-Roza (1991), o esquema freudiano mostra que a articulação entre as representações gera, sobretudo, um efeito de sentido, de modo que o processo de significação não resultaria da ligação da representação-objeto com o referente — que já no próprio esquema freudiano não diz 
respeito a um objeto, mas ao que ele denomina de associações de objeto. De modo contrário, conforme o exposto acima, a significação resultaria dos elos da representação-objeto com a representação-palavra. Tendo em vista a importância deste comentário para os nossos objetivos, vale a pena transcrever, na íntegra, a passagem na qual ele é feito:

"O termo representação-objeto não designa o referente ou a coisa (da qual ele retiraria sua significação), mas, na sua relação com a representação-palavra, designa o significado. A significação não está na coisa, também não está em cada imagem (visual, tátil, acústica, etc.) como se cada uma delas representasse um elemento da coisa, ela resultaria da associação destes vários registros pelos quais se dá a representação. (...) Tudo se passa, portanto, no registro da representação e da associação entre representações." (GARCIA-ROZA, 1991, p.48-49, grifo do autor)

Ainda com respeito ao ensaio freudiano, devemos destacar que, além de assinalar a presença de processos associativos intrínsecos aos domínios das representações-palavra e das representações-objeto, o esquema psicológico também menciona que, no aparelho de linguagem, uma representação-palavra sempre se encontra articulada com outras representações-palavra. Tratar-se-ia do fenômeno da superassociação, o que conduz à caracterização de uma estrutura bastante semelhante à da cadeia significante. Nesta medida, as representaçõespalavra, atreladas ao domínio significante, teriam o poder de criar e de modificar o fenômeno da significação, fazendo com que um sistema de coisas ou objetos seja substituído por um sistema de representações (GARCIA-ROZA, 1991).

Com efeito, de acordo com o modelo freudiano, dizer que o objeto só adquire uma identidade e uma significação a partir do momento em que se articula com uma representação-palavra conduz à concepção de que nenhum ato de percepção se faz com uma independência da linguagem. Assim, a linguagem teria uma função decisiva no processo de produção de sentido, sendo crucial para a constituição de um objeto.

Com base nestes pressupostos, consideramos que a relação do sujeito com os objetos é mediada pelo universo da linguagem e, justamente por este fator, não podemos associar as fantasias vazias ao registro do signo. Nesta perspectiva, seria mais plausível destacar que, na linguagem manifesta nas fantasias vazias, a representação-objeto ligada à representação-palavra assume o peso de um referencial. Deste modo, é justamente este elo entre representação-objeto e representação-palavra que estamos designando de referencial discursivo. Assim, não se trataria, no domínio das fantasias vazias, da apreensão direta do objeto em si, mas de uma forma de discurso que se manifesta como se fizesse referência a um objeto autêntico. Ou seja, aquilo que no regime do signo assume o lugar 
de objeto real, no campo das fantasias vazias, adquire a função de referencial discursivo.

Portanto, nos servimos desta nomenclatura para designar os elementos discursivos que, manifestos nas fantasias vazias, possuem uma significação unívoca, não cambiável e alheia ao processo de formação de símbolos. Nesta perspectiva, o adjetivo 'discursivo', atrelado a estes referenciais, está sendo empregado para, justamente, recuperar o caráter fantasístico destas formações psíquicas, de modo a evitar o possível equívoco de remeter tais referenciais a um dado concreto. Conforme destacamos, o referencial discursivo remete, de fato, ao elo entre uma representação-palavra e uma representação-objeto; no entanto, ainda em referência ao ensaio “Contribuição à concepção das afasias” (FREUD, 1891/1987), esta vinculação entre as duas representações escaparia ao fenômeno da superassociação. Ou seja, de acordo com o assinalado aqui, no regime das fantasias vazias, os processos metonímicos também não se fazem sentir, de forma que elas permaneçam apartadas do restante das produções fantasísticas do sujeito e imunes aos trabalhos da interpretação e da livre associação.

À guisa de conclusão, podemos destacar que quando o pensamento psicanalítico reduz todo o discurso do sujeito ao domínio significante, ele deixa de atentar para outras formas de expressão que, em si mesmas, seriam bastante diversas. Nesta perspectiva, é justamente esta a crítica que estamos traçando: nem tudo no discurso subjetivo deve necessariamente remeter ao domínio significante posto que este domínio se coloca à margem de uma série de fenômenos com os quais nos deparamos na clínica, dentre eles, as fantasias vazias. Trata-se, portanto, de ir contra uma concepção bastante operante no pensamento psicanalítico e de tentar vislumbrar outras formas de discursividade que escapam a esta lógica.

Recebido em 14/3/2007. Aprovado em 3/7/2007.

\section{REFERÊNCIAS}

FOUCAULT, M. (1987) “Nietzsche, Freud e Marx”, in Nietzsche, Freud e Marx: theatrum philosoficum. São Paulo: Princípio.

FREUD, S. (1995) Edição standard brasileira das obras psicológicas completas de Sigmund Freud. Rio de Janeiro: Imago.

(1899) “Lembranças encobridoras", v. III, p.333-357.

(1900) “A interpretação de sonhos”, v. IV e V, p.1-669.

(1908a) “Escritores criativos e devaneio”, v. IX, p.149-162.

(1908b) "Fantasias histéricas e sua relação com a bissexualidade”, v. IX, p.163-173. 
(1910a) “Análise de uma fobia em um menino de 5 anos”, v. X, p.15-157.

(1910b) "Leonardo da Vinci e uma lembrança de sua infância”, v. XI, p.59-125.

(1918) "História de uma neurose infantil”, v. XVII, p.19-157. . (1891/1987) Contribution à la conception des aphasies. Paris: PUF.

GARCIA-ROZA, L. A. (1991) Introdução à metapsicologia freudiana v.1. Rio de Janeiro: Jorge Zahar.

HERZOG, R. (1999) Da falta à ausência de referência: o vazio em psicanálise. Ágora: estudos em teoria psicanalítica, v. II, n.1. Contra Capa: Rio de Janeiro, p.55-73.

JAKOBSON, R. (1963) Essais de linguistique générale. Paris: Minuit.

LACAN, J. (1956-1957/1995) O Seminário livro 4, A relação de objeto. Rio de Janeiro: Jorge Zahar.

(1957/1998) "A instância da letra no inconsciente ou a razão desde Freud”, in Escritos. Rio de Janeiro: Jorge Zahar.

PEIRCE, C. S. (1897/2003) Semiótica. São Paulo: Perspectiva.

PINHEIRO, T. (2002) Escuta psicanalítica e novas demandas: sobre a melancolia na contemporaneidade. Psychê, v.IX, n.9. São Paulo: Unimarco, p.167-176.

SALZTRAGER, R. (2006) "Fantasias vazias: um desafio à clínica psicanalítica”. Tese de Doutorado, Programa de Pós-graduação em Teoria Psicanalítica, Instituto de Psicologia, Universidade Federal do Rio de Janeiro.

Ricardo Salztrager

ricosalz@uol.com.br 